\title{
TECHNOLOGY-ENHANCED LEARNING IN CONSTRUCTION EDUCATION USING MOBILE CONTEXT-AWARE AUGMENTED REALITY VISUAL SIMULATION
}

\author{
Arezoo Shirazi \\ Amir H. Behzadan \\ University of Central Florida \\ 4000 Central Florida Blvd. \\ Orlando, FL 32816-2450, USA
}

\begin{abstract}
Traditional instruction and information delivery methods, as well as memorization are still largely considered the cornerstones of STEM education. Meanwhile, a growing number of students exhibits strong tendency toward technology-based student-centered learning. It is thus imperative that if instructors do not keep up with the pace of technology, soon they will not be able to properly teach students how to effectively work in collaborative and invigorating settings. This paper reports on the findings of an ongoing research that aims at incorporating mobile context-aware visual simulation into STEM education. So far, the authors have used construction and civil engineering as a test bed and developed a mobile augmented reality (AR) visualization platform that allows students to: (1) enhance the contents of their textbooks with computer-generated virtual multimedia and graphics, and (2) interact with context-aware simulated animations. The developed methods have been successfully tested in classroomscale experiments using real student populations.
\end{abstract}

\section{INTRODUCTION}

Integration of knowledge with authentic scientific practice has become the new framework for the next generation of science education standards which are shaped around meaningful contexts and communities that are easy-to-relate for students (Quinn et al. 2011). However, studies indicate that most construction and civil engineering curricula are still relied on traditional teaching methods that are neither adequate to prepare students for onsite tasks nor motivating enough to stimulate their interest in the subject matter for further explorations. In recent years, an increasing number of construction and civil engineering students have exhibited problems in understanding and applying fundamental engineering concepts due to the lack of engaging hands-on experiments and collaborative learning opportunities. As a direct consequence of this problem, many students have to spend a considerable amount of time upon graduation to gain technical and practical knowledge by taking remedial classes or enrolling in employer training programs. Research also shows that the number of students pursuing construction and civil engineering is decreasing especially in North America (Nehdi 2002) due to the (false) common perception among the new generation of technology savvy students that these disciplines are old and thus, cannot keep up with the rapid pace of technology advancements. This lack of motivation has been cited in previous studies as a major cause of not participating, persisting, and putting major effort on the part of students to excel in their education (Keller 1979; Csikszentmihalyi and Csikszentmihalyi 1992; Efklides et al. 2001). Considering these facts, the research presented in this paper aims to design, implement, test, and assess a new technology-based pedagogical methodology based on augmented reality (AR) visualization to support the prospect of a more engaging learning experiment for construction and civil engineering students and instructors. The experimental design of the developed framework is illustrated in Figure 1. In 


\section{Shirazi and Behzadan}

the longer term, this research will seek opportunities to expand its application domain beyond construction and civil engineering and to other STEM disciplines.

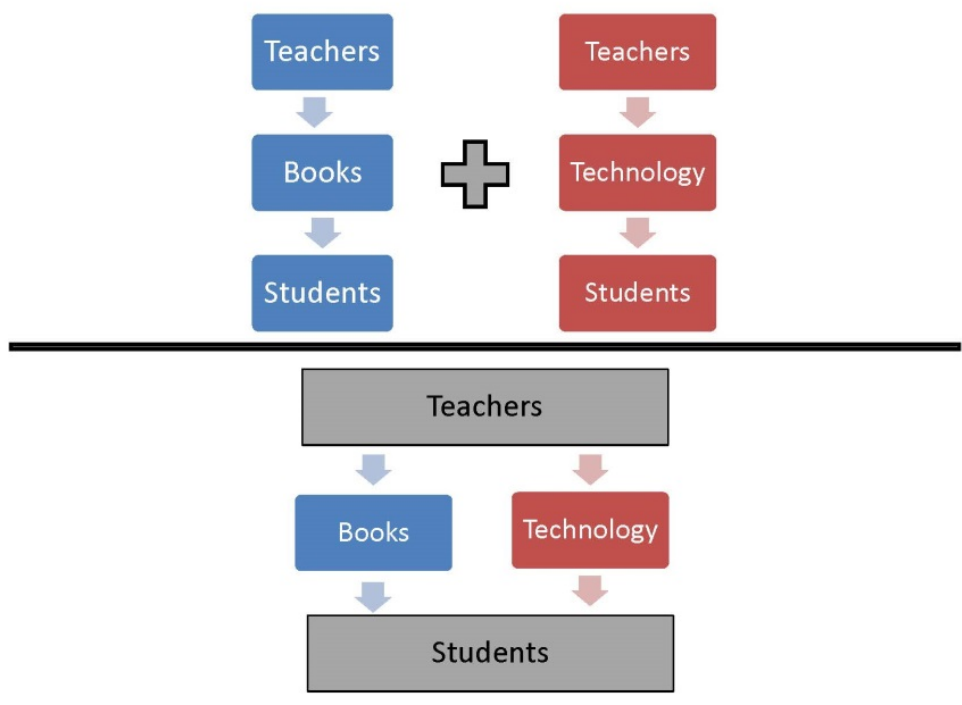

Figure 1: Experimental design used to combine traditional and technology-based learning methods.

During the past few years, AR and tangible user interfaces (TUIs) for tabletop environments have received a lot of attention in educational applications. Researchers have stated that new technology such as virtual reality (VR) and AR have a positive impact on students' motivation (Di Serio et al. 2012). Several empirical studies have been performed to evaluate the impact of AR and TUI platforms on education (Zhong et al. 2003; Dong and Kamat 2011). Despite the variety of disciplines that used these tools, almost all such studies indicated that AR and TUIs can be of great potential to classroom learning. In a nutshell, AR allows the learner to interact with an environment consisting of a mix of real and virtual objects in ways that are not possible otherwise. For instance, scenarios that are hard to create in a pure real world or a digital environment can be conveniently created and simulated in immersive AR. The seamless transition between real and virtual worlds will lead to a new level of educational experience (Billinghurst 2002). However, although several AR and TUI systems have been developed for education, very few have been actually deployed and evaluated in real classroom settings. This has motivated the authors to not only design and implement a mobile context-aware AR visual simulation platform but also systematically integrate and evaluate the effectiveness and real added values of the implemented pedagogical paradigm in enabling students to expand their understanding of basic engineering knowledge.

\section{LITERATURE REVIEW}

\subsection{Augmented Reality and Education}

AR enhances the visual, aural, and tactile senses with virtual or naturally invisible information superimposed on top of the real world. It enables the preservation of the real user environment that provides a reference frame for user actions, thus making a visual and haptic interface which changes the human-computer interaction to a more natural phenomenon (Azuma 1997). In short, AR supplements real-world perception and interaction and allows the user to view a real environment augmented with computer-generated 3D information. The creation of $\mathrm{AR}$ environments requires designing virtual 


\section{Shirazi and Behzadan}

representations and displaying them over the views of the real world. Compared to VR, the model engineering task (the process of creating, filtering, rendering, and displaying the virtual content) in AR is less computationally intensive for it is not necessary to create and render detailed 3D models of objects that are part of and already represented in the real world. Moreover, in mobile AR interfaces that can be launched on smartphones and tablet devices, users can interact with virtual objects without having to wear expensive and bulky equipment such as head-mounted displays (HMDs) (Wojciechowski et al. 2004) while the real-world is conveniently captured by the device built-in camera. This allows users to have a portable and ubiquitous AR tool in their hands that can be launched and used on-demand. While AR simulation and visualization provide potentially transformative benefits, they present unique technological, managerial, and cognitive challenges to the learning process (Dunleavy et al. 2009). For instance, the small size of the screen (in smartphones) and image distortion (considering the limitations of mobile processors) are to certain extents considered as disadvantages of mobile AR applications.

As far as educational values of $A R$ are concerned, scientists have investigated three fundamental principles about the human information processing system for learning: (1) dual channels which refers to people who have separate channels for visual and verbal processing, (2) limited capacity which refers to the limited capacity of human's brain to process several materials simultaneously, and (3) active processing which suggests that meaningful learning occurs when students engage in appropriate cognitive processing (Mayer 2005). Considering these principles, the authors designed and implemented the mobile context-aware AR pedagogical tool to enhance the learning quality by adding visual simulated information to regular textbooks and through engaging students in a more interactive and collaborative classroom environment.

Unlike virtual environments, in AR users are able to directly communicate with one another which can enhance and support the collaboration aspects associated with learning. Previous studies summarized the main potentials of AR applications as improved spatial and practical skills, conceptual understanding, and inquiry-based activities (Cheng and Tsai 2012). Scientists have shown that by allowing users to physically move in the real world (as the spatial context) while interacting with virtual objects, mobile AR applications can create opportunities for better learning with long-lasting impact (Dunleavy et al. 2009). Conducting hands-on experiments facilitates more effective learning that can be directly applied to the real world. Therefore, if properly used, AR not only does combine the real world experience with the learning process, but it can also create interactive and collaborative educational scenarios which motivate students to communicate with each other, focus on the goal of learning the presented contents, and further collaborate and participate in group discussions even outside the classroom. A thorough study of these and several other recent work aimed at evaluating the educational impact of AR has motivated the authors to pursue an inclusive approach to use AR visual simulation in engineering education. In the presented research, and for proof-of-concept experiments and validation scenarios, construction and civil engineering was used as a test bed. However, the findings of this project are ultimately sought to be generalized to and useful in broader areas of STEM education.

\subsection{Related Work in Construction Engineering}

Within the past few years, AR applications have been developed and implemented to assist in collaborative education (Kato et al. 2000; Patel et al. 2005; Walczak et al. 2006). These types of applications can be used to bring unavailable objects such as heavy and expensive instruments into classrooms, simulate hazardous or unsafe scenarios such as construction jobsite operations, or visualize hard-to-explain concepts such as how different tools function. Therefore, AR environments can be a great asset in a wide range of scientific and engineering domains (e.g. math and physics, chemistry, history, engineering). Within the construction engineering domain, AR can be used for onsite information delivery and enhancing field operators' awareness. Dunston (2009) discussed a number of technical issues associated with the application of AR systems in construction including displays, tracking, and calibration. Chen and Wang (2010) presented a framework for multi-disciplinary collaboration, discussed 


\section{Shirazi and Behzadan}

that tangible AR is a suitable system for design collaboration, and illustrated the needs for integrating TUIs and AR systems. Furthermore, Wagner and Schmalstieg (2003) presented a 3D AR navigation application that guides a user to a desired location inside an unknown building. A comprehensive review of visualization applications in construction was presented by Kamat et al. (2010) where the state-of-theart in discrete-event simulation (DES)-based AR and VR visualization as well as the application of AR visualization in field progress monitoring, were reviewed. Regarding the educational and training aspects of AR in construction, Dong and Kamat (2010) presented the design of a robust general-purpose mobile computing framework that allows users to create complex AR visual simulations. More recently, a framework for collaborative AR-based modeling environments for construction engineering was introduced in which location-aware $\mathrm{AR}$ was integrated into the teaching and learning experience (Behzadan et al. 2011).

Despite all such recent efforts, a major gap in knowledge that still remains is the lack of a proper and systematic assessment methodology to evaluate the short and long term benefits of such advanced technologies to the performance of students and trainees. Therefore, the presented research tries to also fill in this gap by conducting a comprehensive performance assessment of the AR pedagogical tool in real classroom settings and presenting the results in a meaningful format to facilitate future research in this area.

\section{BACKGROUND STUDENT SURVEY}

As stated earlier, in this research, construction and civil engineering education was used as a test bed to conduct pilot studies and collect student performance data before and after the implementation of the ARbased pedagogical tool in the classroom. The first step to achieve this goal was to conduct a background student survey. To this end, 166 undergraduate (junior-level) civil, construction, and environmental engineering students were asked to respond to a questionnaire with the goal of collecting information about the familiarity of students with terms such as VR and AR, and gauge their overall interest and opinion about the use of technology in classroom. This survey was administered by the authors during two academic semesters (Fall 2012 and Spring 2013). Figure 2 shows the breakdown of respondents in terms of gender and academic discipline.
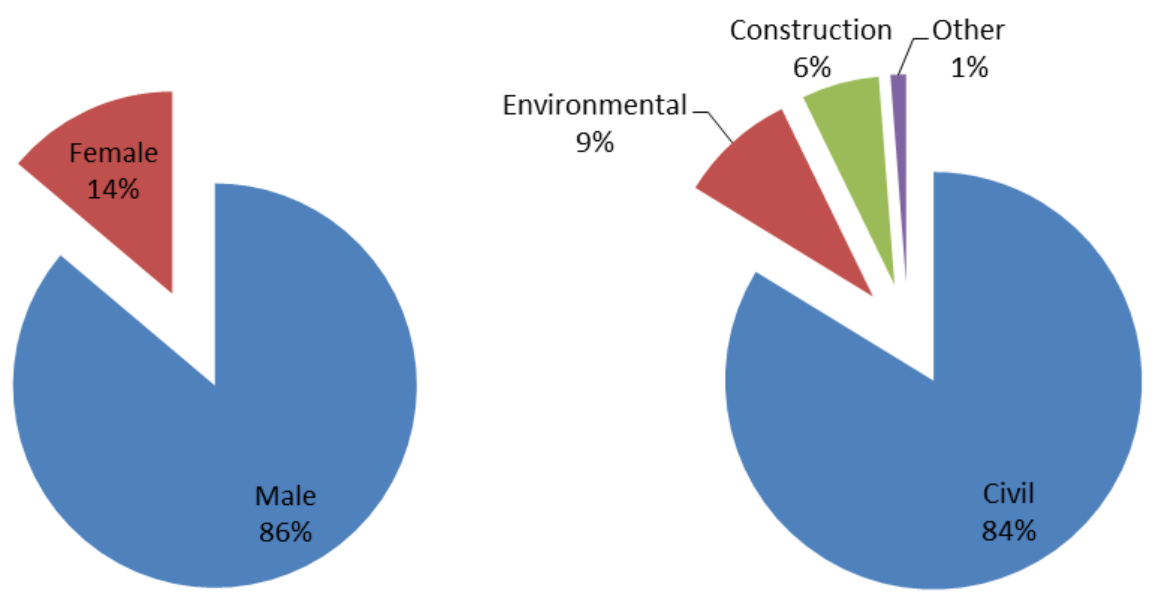

Figure 2: A background survey was conducted using a large engineering student population.

The survey results indicated that a large percentage of students had a good prior knowledge about terms such as VR and AR and also were competent enough to install and use a mobile application on their smartphones or tablet devices. As shown in Figure 3, 92\% of participants responded that they owned a smartphone, a tablet device, or both which by itself, was a clear indication that the latest technology has 


\section{Shirazi and Behzadan}

become a ubiquitous part of students' daily routines and that students have easy access to mobile devices. As far as the learning mechanism is concerned, there are two important components regarding students' awareness of cognitive processing and their control over it, a concept that is commonly referred to as "metacognition" (Harrison 1991): (1) awareness which is to know how one learns, and (2) control which is to know how to monitor and control one's learning. Therefore, the survey also included questions regarding students' awareness of their learning process and their suggestions about using technology and visual information in addition to traditional learning methods. As shown in Figure 4, the survey revealed that $90 \%$ of the students conceived themselves as visual learners and agreed that they would learn better when the instructor used $2 \mathrm{D}$ or $3 \mathrm{D}$ visualization or multimedia to teach abstract engineering and scientific topics. Also, more than $50 \%$ of respondents suggested that they would learn better when working in a collaborative setting and playing a role in a group during the learning process.

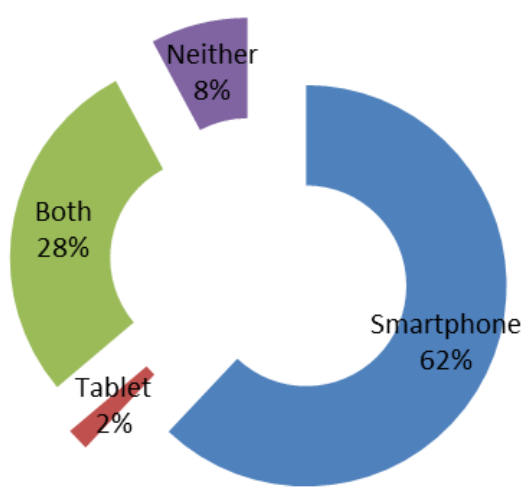

Figure 3: A solid majority of students owned a smartphone, tablet device, or both.

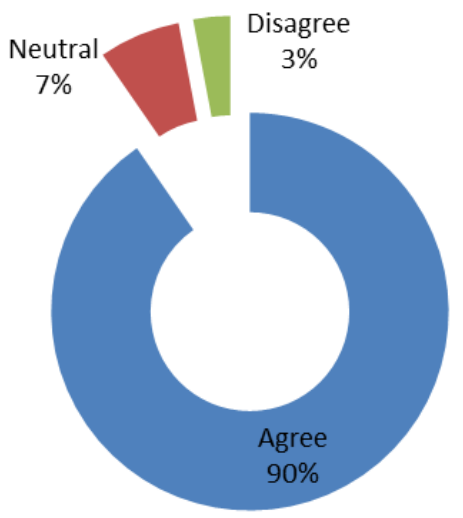

(a)

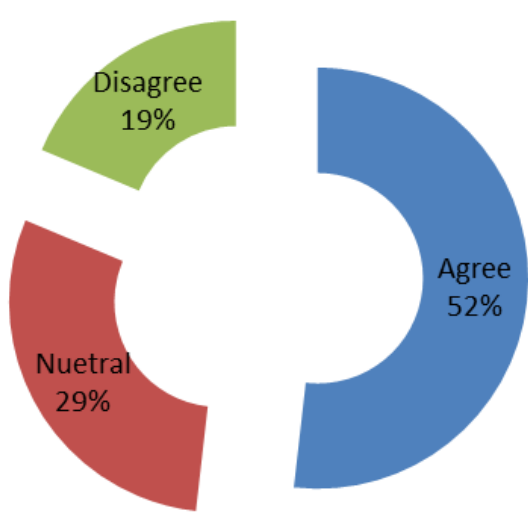

(b)

Figure 4: (a) $90 \%$ of students identified themselves as visual learners, (b) $52 \%$ of students identified themselves as team players.

These observations were also verified by a number of previous studies that stated that most engineering students are visual learners and will learn better when working in collaborative and interactive environments (Felder and Silverman 1988; Dong et al. 2013). Considering the collective results of this and similar surveys, a multi-stage research hypothesis was established that using an interactive and immersive technology-based tool to deliver context-specific visual information to students 


\section{Shirazi and Behzadan}

in a classroom setting will improve their learning experience, increase their knowledge, motivate them to further study and discuss course topics, and help them relate the abstract concepts to real world problems. The rest of this paper will provide a detailed description of the methodology designed to prove this hypothesis. In particular, steps taken to design, implement, and assess a mobile context-aware AR visual simulation tool will be discussed.

\section{SYSTEM DESIGN AND METHODOLOGY}

The pilot study conducted by the authors involved the design of a context-aware AR visual simulation application to deliver on-demand supplementary information about the materials presented in an ordinary engineering textbook to students. It should be noted that the goal of this study was not to completely replace traditional lecture delivery techniques with AR-based information delivery. Rather, the intention was to test whether providing students with this additional layer of visual information will facilitate more interaction between students and foster deeper and more complete learning, given limited face-to-face time instructors can have with every student during the class. The following Subsections will provide a detailed account of the main features and components of the developed mobile AR pedagogical tool. Figure 5 shows screenshots of the experiments conducted using this tool.
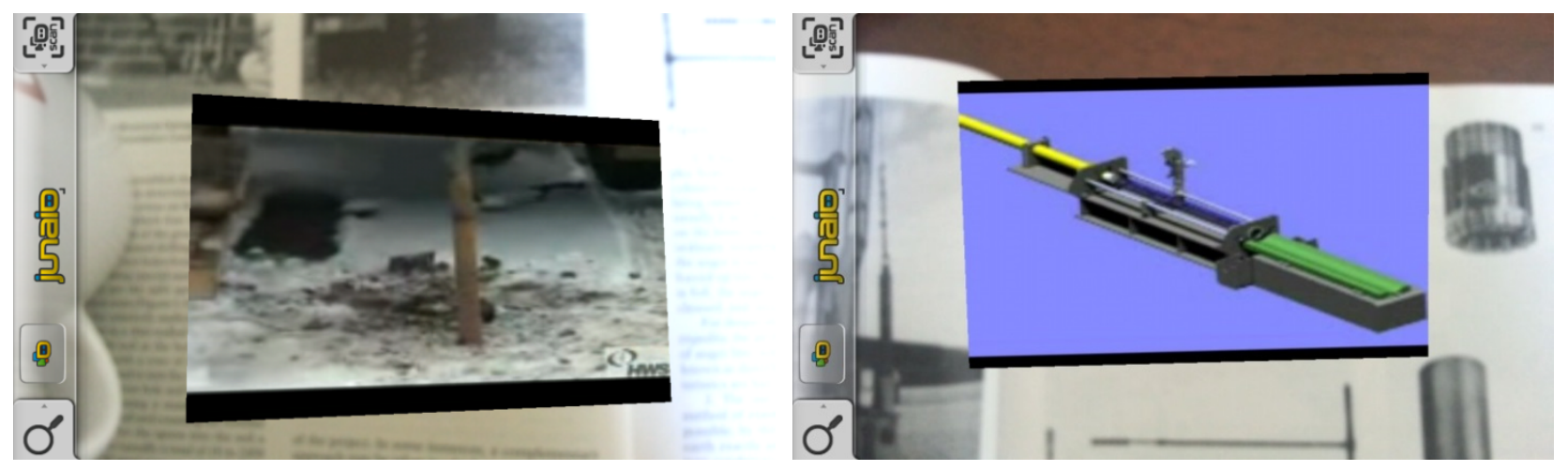

Figure 5: Digital virtual multimedia objects are superimposed over images of a textbook.

\subsection{Input and Output System}

In order to have convincing and realistic AR visualizations, it is necessary that real and virtual contents are fully aligned inside the user's viewing frustum (Kamat and Behzadan 2006). This is achieved through a registration process. There are two major registration techniques in AR visualization: marker-less, and marker-based. A marker is a tracking symbol which is essentially a 2D graphical sign printed on a piece of paper. AR applications that use marker-based registration (a.k.a image-based AR tools) allow developers to link certain virtual content (e.g., video, audio, images, or simulated animations) to each marker. As soon as a marker is visible through the input device (e.g. camera, HMD), virtual information assigned to that marker is overlaid on top of the user's view. In marker-less AR (a.k.a. location-based $\mathrm{AR}$ ), the user can define other conditions for a virtual object to be displayed. For example, the 2D or 3D coordinates of a specific point in the real world can be linked to computer-generated virtual information.

In this research and as shown in Figure 6, each student first uses the built-in camera of his or her webenabled handheld device to scan a printed 2D symbol, known as a Quick Response (QR) code. This is necessary to find the proper context. For instance, each QR code can represent a unique textbook. By scanning this code, the AR application detects the textbook and provides access to the corresponding repository of virtual content. Once the QR code (i.e. context) is detected, students can turn pages and look at different images in the textbook through the viewpoint of the mobile camera (See Figure 7). These images are hereafter referred to as tracking images. As soon as each tracking image is detected by the AR 


\section{Shirazi and Behzadan}

application, students will be able to view supplementary visual contents and interact with the simulated objects to receive information in addition to what is provided in the book.

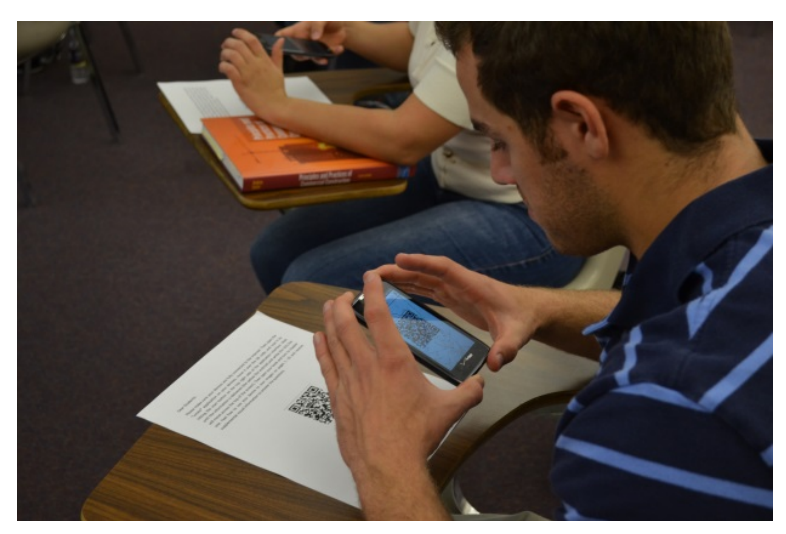

Figure 6: Students use the built-in camera of their mobile devices to scan a QR code.
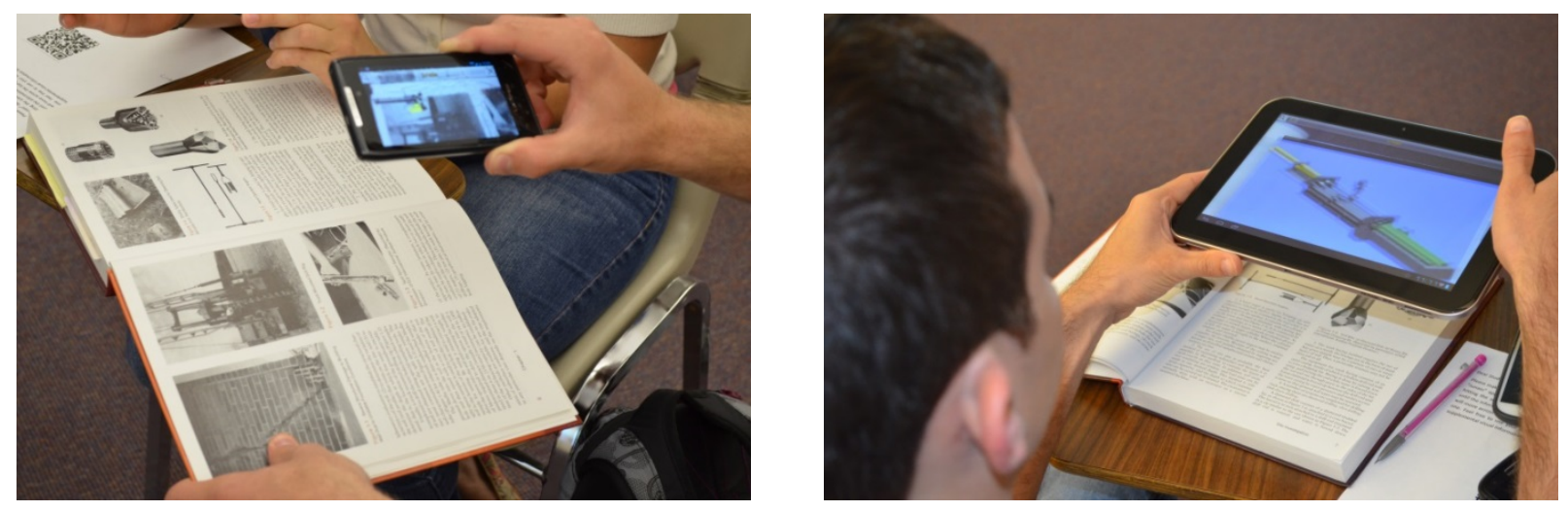

Figure 7: Virtual contents are displayed on student's handheld device for viewing and interaction.

\subsection{Developed AR Software}

In order to develop and implement a scalable design for a mobile AR platform, an open-source third-party web-based programming environment (available for both Android and iOS devices) was used (Junaio 2012). Using this application, virtual computer-generated information are stored on a remote web domain and linked to an online channel (corresponding to a unique QR code representing the context). The benefit of this approach is that all virtual contents are centrally saved and updated on a host server maintained by the application developers. Therefore, there is no need for storing large volumes of information on individual end-user devices. Necessary visual information is downloaded in real time and delivered to each mobile device using the internet (Wi-Fi or $3 \mathrm{G}-4 \mathrm{G}$ mobile connection). This also eliminates the need for updating the virtual content on each and every individual handheld device. Application developers can run a single update on the remote server which will automatically update enduser mobile devices. All data processing and transfer methods used to develop the AR application used in this research are programmed in the Hypertext Preprocessor (PHP) language. 


\section{Shirazi and Behzadan}

\section{VALIDATION AND RESULTS}

The designed AR-based learning tool was tested in an undergraduate construction engineering course at the University of Central Florida (UCF) during the Spring 2013 academic semester. In particular, the authors selected a senior-level undergraduate course (CCE4004 - Construction Methods) with a total enrollment of 16 students to test the hypothesis of this research. A sample chapter from a construction methods and management textbook (Nunnally 2007) that covered topics in construction site investigation and soil sampling was selected and enhanced using computer-generated visual information. The developed tool allowed students to scan different images and graphs inside the book chapter, and receive context-specific virtual information (e.g. 2D and 3D models, video, and sound) as they looked at different pages. Before, during, and after this experiment data was collected about how students described and comprehended the advantages or disadvantages of participating in an AR simulation-based learning environment. In order to study how collaboration can facilitate learning, students were arranged in several groups to work together and discuss their ideas (see Figure 8).

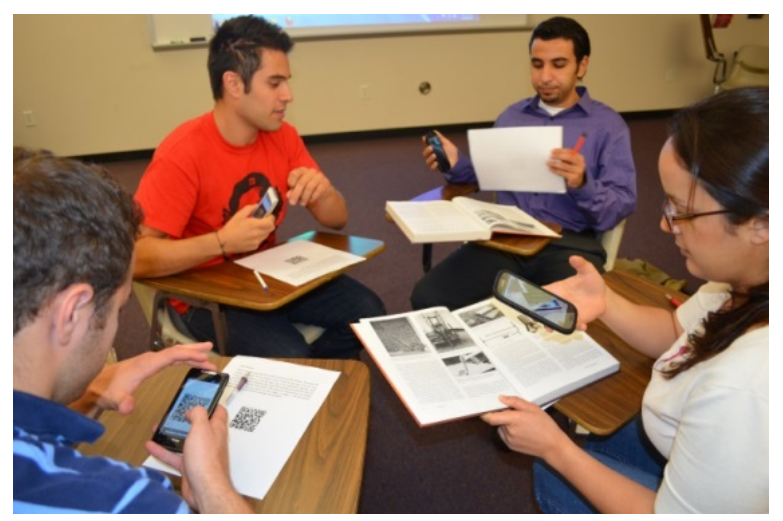

Figure 8: Students worked in groups to discuss their understanding of the topic using the AR tool.

All participants completed the experiment successfully and then filled out an anonymous questionnaire about their experience working with the mobile AR visual simulation platform, as well as reflected on their thoughts about using this or a similar system in the future. Based on the responses received in the post-experiment questionnaire, students reported that the technology-mediated narrative and the interactive, situated, collaborative affordances of the AR simulation were highly engaging, especially among those who had less prior knowledge about the selected course topic. Each statement in the questionnaire was measured according to a five-point Likert scale ranging from 1 (lowest) to 5 (highest). The distribution of responses to two sample questions from this survey are shown in Figure 9, and the results of statistical analysis of each set of responses is presented in Table 1. As shown in this Table, the mean value of Q1 was 4.00 with the standard deviation of 0.76 which is an indication of a high satisfaction rate among students with the new learning procedure. Furthermore, with regards to Q2, the mean was 3.88 and the standard deviation was 0.99 which implies that the majority of students were enthusiastic about using this new AR application in other classes and topics.

A thorough analysis of student responses to the open-ended questions in this questionnaire showed that most of the students found the AR tool very interesting and admitted that it helped them better learn the material by providing more in-depth visual information about the course material. They also thought that the AR tool made the lecture more interactive while still pertaining to relevant topics. However, a few respondents thought that the tool was distracting and in some cases difficult to work with especially when the handheld device was not held properly when scanning images. They preferred to instead, 
receive the same visual information via computer slides. All in all, the students' attitude toward the AR tool was positive and the majority of them found it very to somewhat useful.
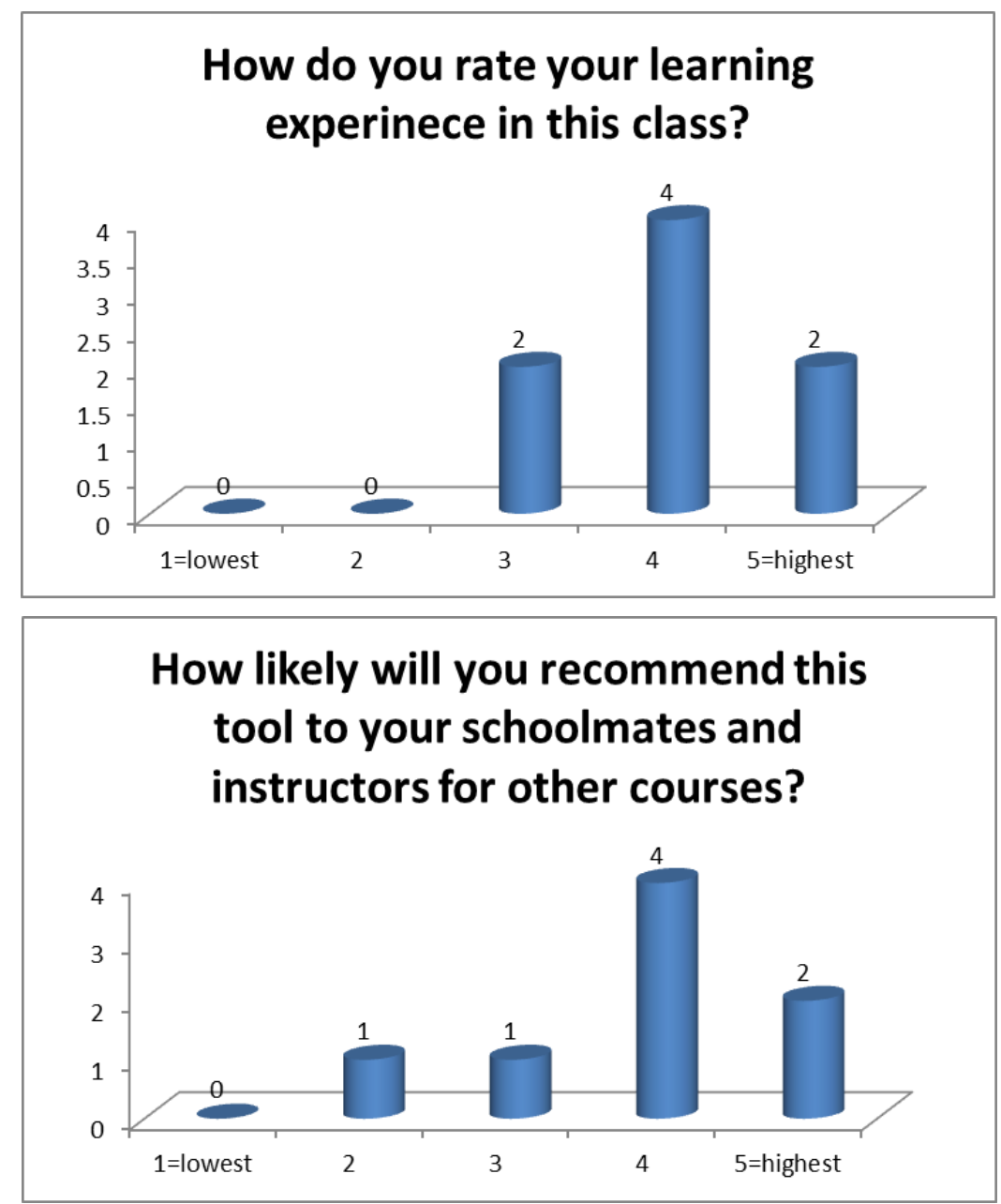

Figure 9: Distribution of responses to sample statements from the post-experiment questionnaire.

Table 1: Statistical analysis of data describing responses to the post-experiment questionnaire.

\begin{tabular}{|l|c|c|}
\hline \multicolumn{1}{|c|}{ Sample Survey Question } & Mean & $\begin{array}{c}\text { Standard } \\
\text { Deviation }\end{array}$ \\
\hline Q1: How do you rate your learning experience in this class? & 4.00 & 0.76 \\
\hline $\begin{array}{l}\text { Q2: How likely is it that you recommend this tool (or a similar AR tool) } \\
\text { to your schoolmates and instructors for other courses? }\end{array}$ & 3.88 & 0.99 \\
\hline
\end{tabular}

\section{CONCLUSIONS AND FUTURE WORK}

The goal of this paper was to present the latest findings of an ongoing study aimed at using context-aware mobile AR to improve the quality of education and training in engineering and science. The authors used construction and civil engineering as a test bed to validate and assess the impact of AR-based learning in classroom settings. In a pilot study conducted by the authors, parts of an ordinary engineering textbook were enhanced using 3D and multimedia visual simulations. Students were then asked to use their smartphones or tablet devices to navigate through the textbook and receive on-demand virtual information 


\section{Shirazi and Behzadan}

corresponding to different figures and diagrams in the book. Data about student performance and satisfaction was collected to validate the real impact of the developed pedagogy on student learning and motivation. A majority of students rated the mobile AR tool as an effective educational platform and suggested that it should be as well used in other courses. In general, it was found that AR visual simulation coupled with collaboration and interaction can provide multiple affordances in support of technology-based and situated learning. Future work in this research will include adding new features such as the ability to deliver location-based information, testing the tool in outdoor environments such as construction jobsites to train workers, assessing the pedagogical aspects using larger and more diverse student and trainee populations, and ultimately, expanding the application domain to other STEM disciplines.

\section{ACKNOWLEDGMENTS}

The presented work has been partially supported by the Engineering Information Foundation (EiF) through grant 13.02. The authors gratefully acknowledge the support from the EiF. Any opinions, findings, conclusions, and recommendations expressed in this paper are those of the authors and do not necessarily reflect the views of the EiF.

\section{REFERENCES}

Azuma, R. T. 1997. "A Survey of Augmented Reality." Presence-Teleoperators and Virtual Environments 6:355-385.

Behzadan, A. H., A. Iqbal, and V. R. Kamat. 2011. "A Collaborative Augmented Reality Based Modeling Environment for Construction Engineering and Management Education." In Proceeding of the 2011 Winter Simulation Conference, Edited by S. Jain, R.R. Creasey, J. Himmelspach, K.P. White, and M. Fu, eds. 3568-3576. Piscataway, New Jersey: Institute of Electrical and Electronics Engineers, Inc.

Billinghurst, M. 2002. "Augmented Reality in Education.” Technical Report No. 12, New Horizons for Learning, Seattle, Washington.

Chen, R. I., and X. Wang. 2010. "Augmented Reality for Multi-disciplinary Collaboration.” Augmented Reality, 220-230.

Cheng, K. H., and C. C. Tsai. 2012. "Affordances of Augmented Reality in Science Learning: Suggestions for Future Research." Journal of Science Education and Technology Springer:1-14.

Csikszentmihalyi, M., and I. S. Csikszentmihalyi. 1992. Optimal Experience: Psychological Studies of Flow in Consciousness, 1st ed. Cambridge CB2 1PR, United Kingdom: Cambridge University Press.

Di Serio, Á., M. B. Ibáñez, and C. D. Kloos. 2012. "Impact of an Augmented Reality System on Students' Motivation for a Visual Art Course." Computers \& Education In Press:1-11.

Dong, S., A. H. Behzadan, F. Chen, and V. R. Kamat. 2013. "Collaborative Visualization of Engineering Processes Using Tabletop Augmented Reality.” Advances in Engineering Software 55:45-55.

Dong, S., and V. R. Kamat. 2010. "Robust Mobile Computing Framework for Visualization of Simulated Processes in Augmented Reality." In Proceeding of the 2010 Winter Simulation Conference, Edited by B. Johansson, S. Jain, J. Montoya-Torres, J. Hugan, and E. Yücesan, eds. 3111-3122. Piscataway, New Jersey: Institute of Electrical and Electronics Engineers, Inc.

Dong, S., and V. R. Kamat. 2011. "Collaborative Visualization of Simulated Processes Using Tabletop Fiducial Augmented Reality." In Proceeding of the 2011 Winter Simulation Conference, Edited by S. Jain, R.R. Creasey, J. Himmelspach, K.P. White, and M. Fu, eds. 828-837. Piscataway, New Jersey: Institute of Electrical and Electronics Engineers, Inc. 


\section{Shirazi and Behzadan}

Dunleavy, M., C. Dede, and R. Mitchell. 2009. "Affordances and Limitations of Immersive Participatory Augmented Reality Simulations for Teaching and Learning." Journal of Science Education and Technology, 18: 7-22.

Dunston, P. S. 2009. "Key Areas and Issues for Augmented Reality Applications on Construction Sites." Mixed Reality in Architecture, Design and Construction Springer: 157-170.

Efklides, A., J. Kuhl, and R. M. Sorrentino. 2001. Trends and Prospects in Motivation Research. 1st ed. Nowell, Massachusetts: Kluwer Academic Publishers, Springer.

Felder, R. M., and L. K. Silverman. 1988. "Learning and Teaching Styles in Engineering Education." Engineering Education 78:674-681.

Harrison, C. J. 1991. "Metacognition and Motivation." Reading Improvement 28:35-39.

Junaio. 2012. “Junaio: Your Mobile Companion.” Last modified December 15 2012. http://www.junaio.com/

Kamat, V. R., and A. H. Behzadan. 2006. "GPS and 3DOF Tracking for Georeferenced Registration of Construction Graphics in Outdoor Augmented Reality.” Intelligent Computing in Engineering and Architecture Springer:368-375.

Kamat, V. R., J. C. Martinez, M. Fischer, M. Golparvar-Fard, F. Peña-Mora, and S. Savarese. 2010. "Research in Visualization Techniques for Field Construction." Journal of Construction Engineering and Management 137:853-862.

Kato, H., M. Billinghurst, I. Poupyrev, K. Imamoto, and K. Tachibana. 2000. "Virtual Object Manipulation on a Table-Top AR Environment." In Proceeding of the 2000 Augmented Reality Conference, 111-119. Piscataway, New Jersey: Institute of Electrical and Electronics Engineers, Inc.

Keller, J. M. 1979. "Motivation and Instructional Design: A Theoretical Perspective." Journal of Instructional Development 2:26-34.

Mayer, R. E. 2005. "Cognitive Theory of Multimedia Learning." The Cambridge Handbook of Multimedia Learning, 31-48.

Nehdi, M. 2002. "Crisis of Civil Engineering Education in Information Technology Age: Analysis and Prospects." Journal of Professional Issues in Engineering Education and Practice 128:131-137.

Nunnally, S. W. 2007. Construction Methods and Management, 7th ed. Upper Saddle River, New Jersey: Prentice-Hall, Inc.

Patel, M., M. White, N. Mourkoussis, K. Walczak, R. Wojciechowski, and J. Chmielewski. 2005. "Metadata Requirements for Digital Museum Environments." International Journal on Digital Libraries 5:179-192.

Quinn, H., H. Schweingruber, T. and Keller. 2011. A Framework for K-12 Science Education: Practices, Crosscutting Concepts, and Core Ideas, 1st ed. Washington, D.C.: National Academies Press.

Wagner, D., and D. Schmalstieg. 2003. "First Steps Towards Handheld Augmented Reality." In Proceedings of the 2003 International Symposium on Wearable Computers, 127-137. Piscataway, New Jersey: Institute of Electrical and Electronics Engineers, Inc.

Walczak, K., R. Wojciechowski, and W. Cellary. 2006. "Dynamic Interactive VR Network Services for Education." In Proceedings of the 2006 ACM Symposium on Virtual Reality Software and Technology, 277-286.

Wojciechowski, R., K. Walczak, M. White, and W. Cellary. 2004. "Building Virtual and Augmented Reality Museum Exhibitions." In Proceedings of the 2004 International Conference on 3D Web Technology, 135-144.

Zhong, X., P. Liu, N. D. Georganas, and P. Boulanger. 2003. "Designing a Vision-Based Collaborative Augmented Reality Application for Industrial Training." IT-Information Technology 45:7-18. 


\section{AUTHOR BIOGRAPHIES}

AREZOO SHIRAZI is a M.S.C.E. student of Construction Engineering at the University of Central Florida (UCF). She received her Bachelor's degree in Civil Engineering in 2012 from University of Tehran (Iran). Her current research interests include mobile augmented reality and visualization, and augmented reality information delivery in design, construction and training. She is a student member of the American Society of Civil Engineers (ASCE). Her email address is arezoo.shirazi@knights.ucf.edu.

AMIR H. BEHZADAN is a Wharton Smith Faculty Fellow and Assistant Professor of Construction Engineering at the University of Central Florida (UCF). He received his Ph.D. in Civil Engineering in 2008 and his Master's degree in Construction Engineering and Management in 2005 both from the University of Michigan, Ann Arbor. He also holds a B.Eng. degree in Civil Engineering from Sharif University of Technology (Tehran, Iran). His current research interests include intelligent and autonomous construction systems, data-driven simulation and visualization, and construction process data mining. He is a member of the American Society of Civil Engineers (ASCE) and the Construction Industry Institute (CII), and serves on the editorial board of the ASCE Journal of Construction Engineering and Management. His email address is amir.behzadan@ucf.edu and his web page is http://pegasus.cc.ucf.edu/ abehzada/. 